\title{
Educación ambiental en el bachillerato: De la escuela a la familia
}

\section{Environmental education in the baccalaureate: From school to family}

\begin{abstract}
Adelina Espejel Rodríguez es profesora investigadora de la Universidad Autónoma de Tlaxcala (México) (adelinaer@hotmail.com) (iD (https://orcid.org/0000-0003-0299-796X)
\end{abstract}

Isabel Castillo Ramos es profesora investigadora de la Universidad Autónoma de Tlaxcala (México) (icastillor@hotmail.com) iD (https://orcid.org/0000-0001-7761-3225)

Recibido: 2019-02-08 / Revisado: 2019-04-01 / Aceptado: 2019-05-20 / Publicado: 2019-07-01

\section{Resumen}

El documento tiene como objetivo mostrar cómo los estudiantes del nivel medio superior (NMS) involucran y concientizan a su familia, a través de acciones prácticas y viables para conservar y cuidar el entorno escolar y comunitario. La investigación se desarrolla en el marco de la metodología cualitativa. La información se recolectó utilizando el método de observación directa o participante; tareas, bitácoras, asimismo se les aplicó un cuestionario con preguntas para respuestas en forma abierta y cerrada. Esta investigación fue realizada en el Centro de Bachillerato Tecnológico Industrial y Servicios 212 (CBTis) de Tetla de la Solidaridad,Tlaxcala, México, en el año 2017. Los sujetos de estudio fueron 85 estudiantes y 282 familiares, vinculados para operar su Programa Ambiental Familiar (PAF) como estrategia operativa. Los datos resultantes del trabajo de campo se sistematizaron y procesaron para facilitar su análisis e interpretación. Los estudiantes aplicaron el PAF, con sus familias, así como enseñar a cada uno de sus integrantes para preservar el medio ambiente. Se concluye que la educación ambiental debe ser de padres a hijos y de hijos a padres, esto permite reforzar su propia conciencia, desarrollar, fomentar valores y conductas amigables con el medio ambiente, para el cuidado y conservación de los recursos naturales. La población mexicana necesita fomentar la cultura ambiental.

Descriptores: Ambiental, jóvenes, bachillerato, comunidad, conciencia, valores.

\begin{abstract}
This paper has as objective to show how baccalaureate students involve and raise awareness within their families through practical and feasible actions to preserve and care for the school and the community environment. Research is developed in the framework of qualitative methodology. The information was collected using participant or direct observation method; homeworks, daily notebooks, it also was applied a questionnaire with questions to answer in open and close form. This research was practiced into Centro de Bachillerato
\end{abstract}

Forma sugerida de citar: Espejel Rodríguez, A., \& Castillo Ramos, I. (2019). Educación ambiental en el bachillerato: De la escuela a la familia. Alteridad, 14(2), 231-242. https://doi.org/10.17163/alt.v14n2.2019.07 
Tecnológico Industrial y Servicios 212 (CBTIs), of Tetla de la Solidaridad, Tlaxcala, México in 2017 year As study subjects were 85 students and their family were 282, linked to applied Family Environmental Program (PAF) as operative strategy. The data resulting from field work were systematized and processed in order to do easy its analysis and interpretation. Students applied the PAF with their families, also teach to each one to preserve the envi-

\section{Introducción}

Ante los problemas ambientales (PA) globales y locales, es necesario implementar en las instituciones educativas modelos o estrategias de educación ambiental (EA) donde se involucren tanto a los estudiantes como a sus familiares para aminorar los PA de México. Por lo tanto, el trabajo tiene como objetivo mostrar cómo los jóvenes del nivel medio superior involucraron a su familia en actividades o acciones ambientales, con la finalidad de crear conjuntamente una conciencia ambiental para mitigar PA de su entorno. En las últimas décadas, a nivel mundial se observa una mayor preocupación por los PA que se muestran en diferentes partes del planeta tierra, razón por la cual cada día se establecen, indagan o innovan estrategias o modelos de EA para las instituciones educativas. La EA debe ser un proceso permanente y transversal en el sistema educativo formal, donde los estudiantes adquieran y fomenten su conciencia, conocimientos, actitudes, conductas, valores, competencias y experiencias prácticas para actuar de forma individual, grupal o colectiva en la resolución o mitigación de los problemas ambientales. No obstante, la EA no sólo debe ser una estrategia de transmisión de información en la educación formal, sino una forma de enseñanza enfocada hacia la labor praxis. Por tanto, "sus resultados deben plasmarse en la vida cotidiana de las familias y de las instituciones gubernamentales y no gubernamentales, además debe llevar un factor de cambio social, apuntando al desarrollo de valores y actitudes ambientales" (Rivas citado en Salinas, 2016, p. 11). ronment. It is concluded that environmental education should be from parents to sons and from sons to parents; its permit reinforce their own conscience, develop and promote environmentally friendly values and behaviors, for care, conservation of natural resources. The Mexican population needs to promote the environmental culture. Keywords: Environmental, young, baccalaureate, community, awareness, value.

La EA, por la forma en que la conciben y la llevan a la práctica en la acción educativa, puede ser expuesta por diferentes corrientes: la naturalista, relacionada con el ecosistema o biósfera, que aprende sobre la naturaleza o experiencial; la conservacionista, que agrupa las propuestas en la conservación de los recursos naturales; la resolutiva, con la cual se trata de informar o de conducir a la gente en el desarrollo de habilidades para resolver PA o mitigarlos; y la acción se acentúa en labores dinámicas (Sauve, 2004). Además, la corriente moral o conducta, se establece en un conjunto de valores y actitudes, conscientes y coherentes entre ellos; mientras que en la sustentabilidad se trata de aprender a utilizar racionalmente los recursos del presente, para asegurar las necesidades básicas del futuro (Sauve citada en Paz, Avendaño, William, \& Parada, 2014).

García Díaz (citado en Morón, \& Morón, 2017, p. 251) indica que existen tres modelos en relación con la EA: a) De corte naturalista, ajustado en la comprensión y conocimiento en los contenidos de las asignaturas relacionadas con el medio ambiente (MA) y en la investigación ambiental; b) De corte ambientalista, donde se busca favorecer, ayudar, respetar, conservar y preservar el medio a través de la sensibilización, motivación, concienciación, conocimiento y capacitación a la población, buscando la mitigación de los PA; y c) Un tercer modelo denominado desarrollo sustentable con la finalidad de utilizar los recursos de forma racional y sostenible para buscar un cambio en la estructura económica, social y ambiental.

En este trabajo, por la forma en que se concibe y se practica, la EA es vista desde las 
corrientes: Resolutiva, porque a los escolares se les informa sobre los PA y ellos mismos, conjuntamente con sus familiares, desarrollan destrezas y estrategias para aminorarlos; práxica, los estudiantes y los integrantes de la familia se sitúan en una visión de labor, de instruirse, y reflexión; también se explica desde la corriente moralistaética, se funda en un conjunto de compromisos y valores ambientales que ellos y los familiares van adquiriendo a través del curso. Asimismo, la EA es vista desde el modelo ambientalista, en el que se trata de beneficiar, ayudar, respetar y conservar el ambiente a través de la sensibilización, concienciación, información y capacitación a la población, para la mitigación de los $\mathrm{PA}$.

En cada una de las corrientes y modelos se busca que la EA sea un instrumento para activar, fomentar y desarrollar la conciencia ambiental, enfocada a originar la participación amigable de la enseñanza, en la conservación, aprovechamiento y mejoramiento del MA, además se acentúa en el logro de actitudes positivas y conductas comprometidas en los sujetos (Morachimo, 1999). También que le permita al individuo evaluar analítica y reflexivamente su posición, conducta y conciencia respecto al medio ambiente (Paz, Avendaño, William, \& Parada, 2014, p. 260).

La conciencia ambiental, cuando se vincula con la EA, es explicada como la cognición, las emociones, la responsabilidad, las prácticas y estilos de vida que el individuo moldea de forma dinámica y activa con su naturaleza (Febles citada en Alea, 2006). Se habla de un conocimiento multidimensional, con diferentes dimensiones (Chuliá, citado en Moyano, \& Jiménez, 2005). $\mathrm{Al}$ respecto, de acuerdo con Gomera (citada en Espejel, \& Flores, 2017), podemos distinguir cuatro (Ver Tabla 1).

\section{Tabla 1. Dimensiones de la conciencia ambiental}

\begin{tabular}{|c|l|}
\hline Afectiva & $\begin{array}{l}\text { - Apreciación del deterioro ambiental, afirmaciones y emociones en cuestiones ambientales. } \\
\text { - Actitud amigable con el entorno, se logra motivar y estimular sentimientos con el fin de sensibilizarse. }\end{array}$ \\
\hline Cognitiva & $\begin{array}{l}\text { - Para obtener información, conocimiento y comprensión sobre el deterioro ambiental. } \\
\text { - Desarrolla habilidades y valores ambientales para la conservación y cuidado del medio ambiente }\end{array}$ \\
\hline Conativa & - Disponibilidad para favorecer actitudes, conductas y valores ambientales para aminorar PA. \\
\hline Dinámica & - Práctica de labores responsables, tanto particulares como sociales. \\
\hline
\end{tabular}

Fuente. Elaboración propia con base en Gomera (2008) y Morachimo en Avendaño (2012).

\section{Educación y familia}

La familia, se ha conceptualizado como la base principal de la especie humana, la cual está constantemente inmersa y relacionada con su naturaleza.

La familia constituye un espacio de relaciones vivenciales y de convivencia donde se expresan sentimientos, emociones, conductas, valores y actitudes diversas asociadas al comportamiento de los seres vivos" (Rojas, 2002, p. 190).
Las familias son la base para inculcar valores de responsabilidad, respeto y disciplina para cuidar de forma amigable su entorno ambiental. La EA debe ser direccionada de la casa a la escuela y a la inversa. La educación escolar debe fortalecer los conocimientos y valores de los jóvenes para cimentarlos de forma congruente con su entorno escolar-familiar. Estos pueden ser de tipo proactivo, por ejemplo, "el amor, honestidad, responsabilidad, tolerancia, humildad, respeto a la dignidad humana, respeto y cuidado al MA, atención a la satisfacción de las necesidades, calidad de la vida, cuidado de la salud y atención 
en la educación" (Rojas, 2002, p. 190). La familia es un espacio donde se transfieren y enseñan valores, nociones e ideales para el progreso de las personas y el cuidado de su entorno.

La EA debe partir de la enseñanza de los padres a los hijos para que la familia sea transmisora de valores y conductas que sirvan para cuidar y conservar el MA escolar y comunitario. En la actualidad se busca que la enseñanza ambiental sea transversal con las diferentes disciplinas para unificar conocimientos y aprendizajes de una realidad cotidiana y empírica.

En el presente trabajo se argumenta a la familia como transmisor y receptor de valores ambientales, siguiendo a Bronfenbrenner (citada en Mathiesen et al., 2002), se le considera como un sistema abierto de gran relevancia para el desarrollo de los sujetos. Pero también

Su función educadora fundamental, responsable de transmitir las normas y valores sociales a sus descendientes y prepararlos para funcionar en el mundo social, ha sido reconocida en todas las culturas a través de la historia (Levy citada en Mathiesen et al., 2002, p. 56).

La familia, junto con la institución educativa, las amistades y las redes de información social, son los principales transmisores de los conocimientos, valores, conductas, actitudes, roles y hábitos que les sirven para desarrollarse como personas racionales dentro de una sociedad (Papalia citada en Mathiesen et al., 2002). En esta investigación, se busca que los jóvenes transfieran los conocimientos ambientales de forma responsable y puntual a los integrantes de la familia, para favorecer la acción ambiental en los hogares y comunidades.

La sociedad forma sus valores a través de la socialización familiar y escolar. El niño o los jóvenes visualizan su entorno de acuerdo a la forma de vivir que ofrece la familia (Loera citado en Fragoso, \& Canales, 2009) los progenitores deben intervenir de forma consciente para formar valores, conocimiento y actitudes que permitan a sus hijos una aproximación con el mundo real. Sin embargo, las instituciones educativas se modelan como un espacio de relaciones con diferentes individuos, que tienen una cultura y saberes distintos a los que se aprenden en casa.

La escuela, se convierte en un lugar privilegiado donde se relacionan con diversos grupos con culturas propias, con formas particulares de valorar el mundo que les rodea y lo complementan con la forma particular que desarrolla en sus aulas para ampliar sus horizontes (Fragoso, \& Canales, 2009, p. 178).

La educación de los jóvenes la van adquiriendo de la experiencia y convivencia familiar, escolar y comunitaria, lo que hace que cada individuo tenga su propia cultura con valores y actitudes diferentes de su entorno. Aunque los lazos más apegados y afectivos para la adquisición de valores es la familia (Fragoso, \& Canales 2009). Por tanto, en este trabajo se analizan los valores ambientales que trasmiten los padres a los hijos o a la inversa, de los jóvenes a los padres, debido a la educación actualizada que adquieren en el transcurso de su educación continua.

Ante esto, los jóvenes participan en un intercambio de comunicación y formación de conocimientos, actitudes y valores ambientales, obtenidos en las instituciones educativas. Buscan involucrarse de forma participativa con cada uno de los integrantes de la familia para coadyuvar, fomentar y desarrollar valores ambientales conjuntamente. Jacometo y Rossato (2017, p. 58 ) alude que "Los lazos afectivos proporcionan apoyo psicológico y social en la familia, ayudando a hacer frente a los problemas cotidianos". En este artículo se describe la forma en que los jóvenes involucran a sus padres, familiares y amigos, para desarrollar y fomentar valores adquiridos en la escuela, con la finalidad de mitigar PA.

\section{Estrategia metodológica}

\subsection{Tipo de investigación}

La investigación se desarrolla en un contexto cualititativo para exponer y deducir las interacciones y las subjetividades (Dieterich, 2003; Gayou, 
2012) de los estudiantes. Esta metodología conceptualizada por Taylor y Bogdan (2000) y Hernández, Fernández y Baptista (2014) como: La que describe la información de forma textual de los individuos ya sea de forma escrita o dialogada. Asimismo, la observación perceptible. Nociones metodológicas que permiten lograr el objetivo planteado en la presente investigación. Para ejecutar la investigación, en primer lugar, el docente de forma didáctica y práctica, aplicó las fases del modelo de EA (Espejel, 2015) a los estudiantes, para motivarlos, proporcionarles información ambiental, aprendieran a desarrollar habilidades, tener valores y compromisos con su entorno, con la finalidad de que los estudiantes fomentaran y acrecentaran su conciencia ambiental, además que sean capaces de trasmitir, establecer y organizar actividades con los integrantes de su familia. Dentro de las acciones del modelo de EA, se plantea un PAF que se considera como una herramienta que contiene una serie de acciones específicas y prácticas (planeadas y propuestas por los estudiantes, de acuerdo a los problemas ambientales de su comunidad), proyectadas para ejecutarse en un periodo determinado, con el propósito fundamental de identificar y mitigar los PA de las instituciones educativas y localidades (Espejel, \& Flores, 2017). Después, los jóvenes llevaron la información y los conocimientos a sus hogares para que sus familiares participaran en la elaboración y ejecución de sus PAF.

\subsection{Muestra y técnicas}

Para llevar a cabo el trabajo de investigación se seleccionó al CBTis 212, que se localiza en el municipio de Tetla de la Solidaridad, Tlaxcala, México; principalmente, porque la institución está aledaña a la zona industrial más importante del Estado y porque el municipio presenta grandes problemas ambientales, tales como: la erosión, deforestación, contaminación por residuos sólidos, contaminación de aire y agua (Espejel, 2009). Asimismo, porque en el CBtis 212 se acredita la asignatura de Ecología, que se imparte en el cuarto semestre del tronco común, sus contenidos están relacionados con la educación ambiental y el desarrollo sustentable. En el estudio participaron 85 estudiantes del cuarto semestre del bachillerato del CBTis 212, que estaban cursando Ecología, del turno vespertino de las especialidades de Logística, Mecatrónica, Programación (A) y Programación (B). Cada estudiante elaboró su PAF con actividades que la misma familia propuso. El total de participantes fue de 367 .

Para la recolección de la información se retomó a la observación directa participante "consiste en obtener impresiones del mundo circundante por medio de todas las facultades humanas relevantes" (Patricia y Adler, citados por Gayou, 2012, p. 104). Esta técnica necesita tener una relación estrecha con los individuos.

Para hacer una indagación y valoración más completa y metódica, se solicitó a los estudiantes que contestaran un cuestionario y entregaran las bitácoras donde plasmaron las actividades del PAF. El cuestionario se organizó en tres partes: a) Aspectos generales, b) Acciones ejecutadas, c) Organización de equipos, d) Satisfacción de acciones realizadas.

\subsection{Sistematización y análisis de la información}

Las observaciones, narraciones de sus bitácoras, proyectos y el cuestionario, nos permitió describir, sistematizar y analizar la información. "El método de análisis descriptivo es el que se utilizó para mostrar los resultados acertados del presente trabajo de investigación” (Espejel, \& Flores, 2017, p. 299). De acuerdo a los objetivos planteados en el proyecto, se retomaron las categorías de análisis de forma lógica y coherente. Para la sistematización se utilizó el programa Excel que permitió organizar, clasificar y categorizar la información. Se consideró que:

El análisis de los datos cualitativos, responden no a la cuantificación de la información sino al proceso de interpretación con el propósito de descubrir conceptos y relaciones en los datos 
brutos, para luego organizarlos en esquemas explicativos. (Strauss, \& Corbin, 2002, p. 20)

\section{Análisis y resultados}

\subsection{Aspectos generales de los participantes}

En la investigación participaron 85 jóvenes del CBTis 212, entre 16 y 17 años, del sexo masculino (35) y del femenino (50), de cuatro especialidades del turno vespertino. Cada estudiante conjuntamente con su familia elaboró su PAF con actividades que entre ellos propusieron.
Los padres (mamá, papá) de los estudiantes que participaron son adultos entre 38 y 44 años en promedio. Los hermanos y hermanas que colaboraron tienen una edad entre 11 y 17 años. Los que más participaron fueron las mamás, posteriormente los hermanos, papás y hermanas, entre otros.

El total de participantes en los PAF fue de 367 sujetos, de los cuales colaboraron principalmente el padre, la madre, el hermano y la hermana; sin embargo, los estudiantes integraron a otros, como amigos, amigas, novia o novio, debido a que sus progenitores por su trabajo no podían participar en todas las actividades (Ver Tabla 2).

Tabla 2. Participantes en los PAF de los estudiantes del NMS

\begin{tabular}{|c|c|c|c|c|c|c|c|}
\hline & Total & & Total & & Total & & Total \\
\hline Alumnos & 85 & Padres & 49 & Madres & 76 & Hermanos & 51 \\
\hline Hermanas & 42 & Tíos & 8 & Tías & 9 & Abuela & 7 \\
\hline Abuelo & 3 & Primas & 4 & Primos & 7 & Amigos & 4 \\
\hline Amigas & 1 & Novio & 2 & Sobrinas & 3 & Sobrinos & 6 \\
\hline Cuñada & 3 & Esposo & 1 & Vecina & 1 & Vecino & 2 \\
\hline Otros & 3 & Total final & & & & & 367 \\
\hline
\end{tabular}

Fuente: Elaboración de las autoras.

En cuanto a las actividades laborales y escolares de la familia, se halló que la mayoría de los papás de los estudiantes son empleados, obreros y comerciantes, sólo $9 \%$ son profesionistas. Mientras que $18 \%$ de las mamás son empleadas, $37 \%$ amas de casa y sólo 3\% son profesionistas. Este último dato es relevante porque sugiere la razón por la que participaron más con los hijos para realizar el PAF. La mayor parte de los hermanos y hermanas que colaboraron son estudiantes.

\subsection{Sensibilización-motivación y conocimiento ambiental a los integrantes de la familia}

Para llevar a cabo su PAF, los estudiantes tuvieron que informar a sus papás de las actividades ambientales que debían consumar en familia. En un principio, a los escolares se les dificultó convencerlos, sin embargo, cuando explicaron los objetivos y la importancia de cuidar el 
MA, los padres accedieron a apoyar y participar en el trabajo de ecología. Cabe mencionar que las familias se fundamentan en sentimientos de amor y solidaridad, para preservar lazos afectivos y realizar proyectos de manera compartida (Jacometo, \& Rossato, 2017).

Se muestran algunos testimonios:

En primer lugar, llegué a casa y les comenté que la profe nos había dicho en clase acerca del cuidado del medio ambiente y lo que puede pasar en unos años si seguimos sin tener conciencia, así que les dije que la profesora nos había dejado de tarea realizar un proyecto ecológico en el que hagamos algunas actividades que beneficien al medio ambiente. Al explicarles me notaron emocionado y con ganas de comenzar a trabajar lo que motivó a mi familia a seguir mis pasos y a integrarse para hacer conciencia y ayudar al medio ambiente. (Pablo, Mecatrónica)

Posteriormente, los jóvenes sensibilizaronmotivaron a los integrantes de la familia, a través de los conocimientos adquiridos en el aula, sobre el deterioro ambiental para que comprendieran la importancia de implementar acciones ambientales. Los estudiantes mostraron el documento de "Carta 2070", imágenes de los PA de su comunidad y les platicaron el argumento de la película "La verdad incómoda" de Al Gore. Esta información, como afirma Rivas (citado en Salinas, 2016), impactó y sensibilizó a la familia. Las generaciones futuras y actuales requieren valores y sentimientos amigables con el MA para el cuidado y conservación de los recursos naturales. Así como estar familiarizados con el medio ambiente, para lograr actitudes amigables con la naturaleza (Kollmuss, \& Agyeman, 2002).

Los estudiantes mostraron que habían fomentado, desarrollado e incrementado una conciencia ambiental a sus familiares, ya que decidieron apoyar con las actividades proyectadas en sus PAF. Asimismo, comprendieron y reflexionaron que también tendrían beneficios al cuidar su ambiente. Molano y Herrera (2014) argumentan que además de lograr actitudes y conductas favorables con el MA se busca pasar del discurso a la práctica.

Yo le comenté a mis padres que este proyecto familiar es para cuidar nuestro MA, para poder mantener saludable a nuestro planeta $y$ poder vivir unos cuantos años más, al respecto mi familia entendió, reflexionó, concientizó y me empezaron ayudar (juntar botellas, focos ahorradores, pilas, carteles, ahorro de agua, etc.). (Mauricio, Logística)

\subsection{Organización y planeación para llevar a cabo el PAF}

Cada estudiante se organizó de diferente manera para plasmar y diseñar su PAF, algunos analizaron todos los PA que hay en la comunidad y a partir de éstos establecieron las metas y las acciones para mitigarlos. El estudiantado en el curso de ecología aprendió que primero se debe elaborar un diagnóstico ambiental para tener conocimiento de lo local a lo global:

Primero, nos sentamos para platicar y discutir sobre los PA que hay en la comunidad y cuáles podíamos disminuir con actividades viables, posteriormente planeamos las acciones que íbamos a realizar durante todos los meses, para combatir la contaminación que hay en la comunidad, nos organizamos conforme a lo que cada uno quería hacer, para mejorar el MA y el entorno de la comunidad. (Alberto, Programación-B)

Otros jóvenes, de forma individual, planearon las actividades ambientales de su PAF y después invitaron a su familia a participar. Cada integrante de la familia seleccionó la actividad ambiental que más les agradaba. Los estudiantes planearon sus actividades de su PAF con acciones fáciles y factibles que pudieran realizarse en poco tiempo, ya que algunos familiares trabajaban y no estaban disponibles para llevar a cabo labores complejas. Cada vez que a alguien se le ocurría una idea, la comentaban y la ampliaban para ver 
cuál era la más acertada y que tuviera un impacto mayor en la naturaleza.

Las actividades se proyectaron y realizaron de acuerdo a los tiempos de los integrantes de la familia, unas veces en la mañana, otras en la tarde. Algunos decidieron hacer las más difíciles el sábado, ya que apoyaba el papá con las acciones donde se necesitaba mayor fuerza. Asimismo, el fin de semana trabajaban en la comunidad.

Algunas veces no se lograban ejecutar todas las actividades planeadas, pues se presentaron problemas, tales como: falta de tiempo, poco interés, decepción, ya que recogían la basura y al otro día ya estaba sucio; por falta de salud y fatiga de los abuelos, por los horarios que tenían que cumplir, falta de creatividad y conocimientos, por mal tiempo, mala comunicación, falta de herramientas y por impuntualidad.

\subsection{Acciones ejecutadas por los inte- grantes de la familia}

Los jóvenes elaboraron su PAF con la finalidad de concientizar y enseñar a los integrantes de su familia a cuidar el MA, para que sus hijos puedan gozar y tener una mejor calidad de vida. Los PAF han fomentado una conciencia ambiental y una colaboración dinámica, favoreciendo la conjunción escuela-comunidad (Acosta, Fuenmayor, León, \& Sayago, 2006). En la estructura del PAF se contempla un objetivo, nombre de la familia o nombre del equipo, comunidad donde se aplica, PA a mitigar, acciones viables, fecha e integrantes de la familia que lo ejecutan.

La mayor parte de los estudiantes llevaron a cabo su PAF con el propósito de impulsar la conciencia ambiental en los integrantes de su familia sobre el daño que se está ocasionando al MA, así como recomendar ser más cuidadosos con las actividades cotidianas y laborales que contaminan su entorno. La EA es una motivadora de la conciencia ambiental, enfocada a causar la intervención dinámica de la enseñanza-aprendizaje para la conservación y preservación del MA (Morachimo, 1999). Ejemplos de esta labor es el siguiente testimonio:

Debemos crear conciencia en cada uno de los integrantes de la familia, con la finalidad de que participemos unidos en la ejecución de actividades ambientales, para lograr un medio ambiente más limpio y por lo tanto tener un mejor futuro para nuestros hijos. (Verónica, Logística)

Los estudiantes también se plantearon en sus objetivos, prevenir, evitar, controlar y mitigar los problemas ambientales para tener un planeta más limpio y puedan disfrutarlo con la familia. Asimismo, ser voces ecológicas para informar a la familia, vecinos y demás personas del grave problema de contaminación que se está causando, el cual se debe disminuir con diferentes propuestas y soluciones prácticas.

Los principales PA que combatió la familia fueron la contaminación de residuos sólidos y la de áreas verdes maltratadas, donde se organizaron el mayor número de acciones para mitigarlos. La mamá y el estudiante fueron los que más participaron; para la contaminación del suelo se realizaron menos labores ambientales.

En la tabla 3 podemos ver los integrantes de la familia, así como su participación en número de faenas para mitigar los PA de su escuela o comunidad. Las acciones ambientales que más realizaron fueron: recoger basura, separar y reciclar, no desperdiciar y reutilizar el agua, limpieza de áreas verdes, conferencias, pláticas, hacer compostas, limpiar lagunas, ríos y calles, recolectar agua pluvial, plantar árboles y plantas, así como regarlos, poner botes para basura y carteles. 
Tabla 3. Participación de la familia en actividades ambientales

\begin{tabular}{|c|c|c|c|c|c|}
\hline Problemas ambientales que mitigaron & Papá & Mamá & Hermano & Hermana & Alumno \\
\hline Contaminación de residuos sólidos & 25 & 51 & 33 & 17 & 62 \\
\hline Áreas verdes maltratadas & 30 & 56 & 24 & 20 & 61 \\
\hline Deforestación & 23 & 42 & 19 & 18 & 49 \\
\hline Desperdicio y contaminación de agua & 23 & 47 & 19 & 20 & 54 \\
\hline Contaminación visual & 15 & 20 & 11 & 13 & 27 \\
\hline Falta de valores ambientales & 26 & 42 & 11 & 17 & 47 \\
\hline Contaminación del suelo & 7 & 9 & 7 & 5 & 9 \\
\hline
\end{tabular}

Fuente: Elaboración de las autoras.

Los estudiantes, junto con su familia, se propusieron acciones ambientales para mitigar el problema de los residuos sólidos, principalmente quieren contribuir para tener un ambiente sano, limpio y saludable, además ayudar a la economía familiar, vendiendo material reciclable y de esta manera valorar más su entorno. Alfie (citado en Molano, \& Herrera, 2014, p. 193) aluden a que "la formación ambiental busca la toma de conciencia y la responsabilidad para lograr la solución al deterioro ambiental".

Al llevar a cabo este proyecto, nos dimos cuenta de muchos lugares contaminados, con mucha basura que las personas tiran. Entonces, decidimos contribuir con nuestra comunidad recogiéndola para que las personas se den cuenta de que lo que hacen está muy mal. (Carolina, Mecatrónica)

El estudiantado y su familia planearon actividades para dar solución al problema ambiental de las áreas verdes maltratadas y la deforestación, principalmente para apoyar al MA, tener áreas con sombra, un clima agradable, una buena calidad de vida, mayor fauna, ubicar árboles en lugares apropiados, rehabilitar áreas áridas, mayor oxígeno, cuidar el planeta para que los árboles y las plantas estén en óptimas condiciones, mejorar la apariencia de la comunidad para hacer conciencia en los niños y los adultos, y evitar enfermedades.

Mi mamá y yo decimos hacerlo porque es muy importante mantener nuestros parques limpios y que tengan un buen aspecto, porque es donde más juegan los niños pequeños. $\mathrm{Y}$ se ve muy mal que los lugares donde juegan estén maltratados y sucios de basura, ya que debido a ello pueden contraer enfermedades. (Martha, Programación-B)

La familia decide hacer acciones para no desperdiciar y contaminar el agua porque considera que es necesario tener conciencia ambiental, ya que algún día se puede acabar o escasear. Además, no quieren quedarse sin este líquido vital, ya que no les agrada la idea de que sus hijos y nietos a futuro no la puedan disfrutar o simplemente no puedan satisfacer sus necesidades de la vida cotidiana. Los integrantes de la familia valoran el agua porque saben que es muy importante para la existencia de la tierra y sin ésta la vida sería un desastre, por ejemplo, ya no habría producción agrícola, los lagos y ríos quedarían secos y esto implicaría ya no trabajar por dinero, sino por el recurso hídrico.

El agua es algo vital para nuestra vida en la tierra y si se acaba sería un desastre, por eso debemos cuidarla ya que este líquido es muy importante para nuestra existencia en la tierra. Pues sin ella no podríamos vivir, porque es muy importante para nuestra hidratación como para las cosechas y animales que existen en el planeta tierra. (Magdalena, Programación-A)

La falta de valores ambientales es otro problema que combatió el estudiantado con la familia, principalmente porque observaron que 
la gente no tiene el hábito de cuidar su MA. Los estudiantes quieren cambiar su forma de pensar y de educar a las nuevas generaciones en el ámbito ambiental, con la finalidad de que tengan un mejor o igual entorno en el futuro. La principal idea fue la de concientizar a la población para cuidar y preservar los recursos naturales:

Porque la contaminación en todos los aspectos, es algo que afecta la vida del ser humano, pero a veces algunas personas no hacen nada para cuidar el ambiente, ya que nos saben cómo hacerlo, lo mejor es orientarlos para que ya no siga creciendo esta problemática en las comunidades. (Irma, Logística)
A los diferentes integrantes de la familia les gustó participar en el PAF, principalmente para contribuir y cuidar su entorno e interactuar con la naturaleza y por la convivencia que se establece entre ellos, asimismo para fomentar e incrementar la conciencia ambiental. Sólo el papá y el estudiante mencionan que para dar ejemplo a los hijos. La hermana y el hermano son los únicos que aluden que hacer acciones ambientales es una experiencia agradable. Levy (citado en Mathiesen et al., 2002) menciona que una de las funciones de la familia es transmitir valores de toda índole, para funcionar y actuar en el mundo social y ambiental (Ver Tabla 4)

Tabla 4. Por qué les gustó realizar el PAF a los integrantes de la familia

\begin{tabular}{|c|c|c|c|c|c|}
\hline & Papá \% & Mamá \% & Hermana \% & Hermano \% & Estudiante \% \\
\hline Para dar ejemplo a los hijos y familia & 30 & & & & 5 \\
\hline Para contribuir y cuidar al MA & 60 & 41 & 57 & 25 & 50 \\
\hline $\begin{array}{l}\text { Tener interacción con la naturaleza y } \\
\text { por la convivencia de la familia }\end{array}$ & 10 & 18 & & & 20 \\
\hline Satisfacción de cuidar el MA & & & & 25 & 15 \\
\hline Para tener y fomentar la conciencia & & 35 & 14 & 12 & 10 \\
\hline Experiencia agradable & & & 29 & 38 & \\
\hline Otros & & 6 & & & \\
\hline
\end{tabular}

Fuente: Elaboración de las autoras.

Algunos de los testimonios:

Es un ejemplo que le damos a nuestros hijos y que nuestros hijos les darán a nuestros nietos, de esta manera hacemos conciencia sobre cómo cuidar el medio ambiente para tener un futuro. Me gustó mucho al hacer las actividades, me divertí cuando plantamos los árboles y juntamos toda la basura de las calles. (Papá y hermana)

\section{Discusión y conclusiones}

La familia es la base para transmitir valores y conductas amigables con el MA, para el cuidado, conservación y preservación de la naturaleza; sin embargo, es ineludible incrementar el conocimiento, fomentar y desarrollar la conciencia ambiental para involucrarse en acciones prácticas y viables del contexto familiar, escolar y comunitario. Jiménez citado en Apaza (2014) afirma que la conciencia ecológica se fomenta en la familia y se refuerzan valores aprendidos en el hogar, manifestándose en acciones cotidianas ambientales que optimicen los entornos de vida en la comunidad.

Cabe mencionar que la población mexicana necesita fomentar la cultura ambiental, por tal motivo la EA familiar debe ser retroalimentada con los conocimientos y experiencias que adquieran los educandos en los diversos niveles educativos, con la finalidad de que converjan en la actualización de la información para la actuación práctica y factible de los PA globales y locales.

La institución educativa del NMS tiene la tarea de formar jóvenes competentes que 
contribuyan al desarrollo sustentable de manera crítica, reflexiva y argumentativa para favorecer la solución y mitigación de los PA en los ámbitos de su entorno. Esta es una de las competencias genéricas que marca la Reforma Integral de la Educación Media Superior (RIEMS) la cual deben desarrollar los estudiantes del NMS "contribuir al desarrollo sustentable de manera crítica con acciones responsables y asumiendo una actitud que favorezca la solución de problemas ambientales en los ámbitos local, nacional e internacional" (Diario Oficial, 2008, p. 5).

La forma de llevar y aplicar proyectos ambientales en las instituciones del bachillerato permite que los estudiantes y su familia adquieran las siguientes ventajas: incrementar la convivencia y tiempo con la familia, desarrollar la habilidad de comunicación y convencimiento, incrementar la conciencia ambiental, aprender a disminuir costos de luz, agua y aprender a planificar y ejecutar actividades ambientales. Remacha y Belletich (2015) y Rodríguez Vargas y Luna (2010) señalan que los proyectos amplían habilidades creativas en los estudiantes principalmente cuando se conforman en equipos para la realización de labores compartidas. Además, el aplicar este tipo de proyectos de EA, genera emociones de bienestar, agrado, estimulación, desolación y afecto al involucrarse en el cuidado y conservación del entorno, ya que permite que se incluyan integrantes de la familia desde niños hasta adultos y amistades, lo que hace que la convivencia entre familia-naturaleza, sea más agradable.

Los jóvenes instruidos y capacitados del CBTis 212 son entes activos en habilidades y conocimientos ambientales, para ejecutar programas o proyectos viables para concientizar a los integrantes de la familia y para proponer acciones encaminadas a aminorar el deterioro ambiental de su localidad.

En suma, la EA debe ser orientada de la familia a la escuela y viceversa para fortalecer los conocimientos, habilidades, valores, actitudes y conductas de los jóvenes y de los integrantes del grupo familiar para lograr un entorno congruente con su realidad. "La educación es un proceso de toma de conciencia, cambio de actitudes y valores, adquisición de conocimientos y desarrollo de habilidades, dirigido a la protección y cuidado del ambiente" (Tovar-Gálvez, 2017 p. 523).

\section{Referencias bibliográficas}

Acosta, C., Fuenmayor, B., León, E., \& Sayago, A. (2006). Programa innovador de educación ambiental para la población indígena añú en la Laguna de Sinamaica. Omnia. 12(3), 123-150.

Avendaño C., W. (2012). La educación ambiental (EA) como herramienta de la responsabilidad social (RS). Revista Luna Azul, (35), 94-115.

Apaza Quispe, J. A. (2014). La conciencia ecológica en el consume de productos en la ciudad de Puno-Perú. Revista de Investigación en Comunicación y desarrollo 5(2), 5-12.

Alea, A. (2006). Diagnóstico y potenciación de la educación ambiental en jóvenes universitarios. Odiseo, Revista electrónica de pedagogía, 3(6), 1-29.

Diario Oficial (2008). Acuerdo número 444 por el que se establecen las competencias que constituyen el marco curricular común del sistema nacional de Bachillerato. Diario Oficial de la Federación, 21 de octubre.

Dieterich, H. (2003). Nueva guía para la investigación científica. México: Ariel.

Espejel, A. (2009). Problemas ambientales procedimiento metodológico y acciones de mitigación en el estado de Tlaxcala. México: Universidad Autónoma de Tlaxcala/Universidad de Camagüey.

Espejel, A. (2015). Educación ambiental, enseñanzas prácticas para el nivel medio superior. México: Universidad Autónoma de Tlaxcala

Espejel, A., \& Flores, A. (2017). Experiencias exitosas de educación ambiental en los jóvenes del bachillerato de Tlaxcala, México. Revista Luna Azul, (44), 294-315. DOI: 10.17151/ luaz.2017.44.18

Fragoso, E., \& Canales, E. (2009). Estrategias educativas para la formación en valores desde la 
educación informal de la familia. Educere, 13(14), 177-185.

Gayou, J.L. (2012). Cómo hacer investigación cualitativa: fundamentos y metodología. México: Paidós Educador.

Gomera, A. (2008). La conciencia ambiental como herramienta para la educación ambiental: conclusiones y reflexiones de un estudio en el ámbito universitario. Universidad de Córdoba, España. (https://bit.ly/2QcWFNK) (2018/02/10).

Hernández Sampieri, R., Fernández Collado, C., \& Baptista Lucio, P. (2014). Metodología de la investigación. México: Mc Graw Hill.

Jacometo, M., \& Rossato, A. (2017). Relaciones familiares versus aprendizaje: un análisis con niños de 5 y 6 años. Alteridad, 12(1), 55-66

Kollmuss, A., \& Agyeman, J. (2002). Mind the Gap: why do people actenvironmentally and what are the barriers to proenvironmental behavior. Environmental Education Research, 8(3), 239-260, https://doi.org/10.1080/13504620220145401.

Mathiesen, M.E., Mora, I., Chamblas, G., Navarro, M., \& Castro, M. (2002). Valores y familia en estudiantes de enseñanza media de la Provincia de Concepción. Revista de Psicología, 9(2), 55-74.

Morón, H., \& Morón. C. (2017). ¿Educación Patrimonial o Educación Ambiental?: perspectivas que convergen para la enseñanza de las ciencias. Revista Eureka sobre Enseñanza y Divulgación de las Ciencias, 14(1), 244-257.

Molano, A., \& Herrera, J. (2014). La formación ambiental en la educación superior: una revisión necesaria. Revista Luna azul, (39), 186-206.

Morachimo, L. (1999). La educación ambiental: tema transversal del currículo. Módulo Ontológico, Centro de Investigaciones y Servicios Educativos - Pontificia Universidad Católica del Perú. Lima: Perú, Pontificia Universidad Católica del Perú.

Moyano, E., \& Jiménez, M. (2005). Los andaluces y el medio ambiente. Andalucía: Consejería de Medio Ambiente, Junta de Andalucía.

Paz, M., Avendaño C., William, R., \& Parada, A. (2014). Desarrollo conceptual de la educación ambiental en el contexto colombiano. Luna Azul, (39), 250-270.

Remacha, A., \& Belletich, O. (2015). El método de aprendizaje basado en proyectos ( $\mathrm{ABP}$ ) en contextos educativos rurales y socialmente desfavorecidos de la educación infantil. Perspectiva Educacional, Formación de Profesores, 54, 90-109.

Rojas, M. (2002). Aprendizaje transformacional en la familia y en la educación. Revista Venezolana de Análisis de Coyuntura, 8(1), 189-200.

Rodríguez, E., Vargas, E., \& Luna, J. (2010). Evaluación de la estrategia 'aprendizaje basado en proyectos'. Educación y Educadores, 13, 13-25.

Salinas, D. (2016). Educación ambiental para el desarrollo y consumo sustentable en Chile. Una revisión bibliográfica. Revista Electrónica Educare, 20(2), 1-15.

Sauvé, L. (2004). Una cartografía de corrientes en educación ambiental. En Michèle Sato e Isabel Carvalho (Orgs.), A pesquisa em educação ambiental: cartografi as de uma identidade narrativa em formação. Porto Alegre. (https://bit.ly/2Jylu6m) (2018/10/01).

Strasuss, A., \& Corbin, J. (2002). Bases de la investigación cualitativa. Técnicas y procedimientos para desarrollar la teoría fundamentada. Colombia: Universidad de Antioquia.

Taylor, S.J., \& Bogdan, R. (2000). Introducción a los métodos cualitativos de investigación. La búsqueda de significados. Barcelona: Paidós.

Tovar-Gálvez, J. (2017). Pedagogía ambiental y didáctica ambiental: tendencias en la educación superior. Revista Brasileira de Educação, 22(69), 519-538. 